\title{
Multi-Detector Row Computed Tomography Urography (MDCTU) in the Evaluation of Microscopic Hematuria in Adults
}

\author{
Mohamed A. Mahmoud1, Mustafa Z. Mahmoud1,2*, Mohammed A. Ali Omer,4, \\ Mohamed E. M. Garalnabi ${ }^{4}$, Ahmed Abukonna1, Maram A. Fagiri ${ }^{1}$ \\ ${ }^{1}$ Basic Sciences Department, College of Medical Radiological Sciences, Sudan University of Science and \\ Technology, Khartoum, Sudan \\ ${ }^{2}$ Radiology and Medical Imaging Department, College of Applied Medical Sciences, Salman Bin Abdulaziz \\ University, Al-Kharj, Kingdom of Saudi Arabia \\ ${ }^{3}$ Department of Radiologic Technology, College of Applied Medical Sciences, Qassim University, Al-Qassim, \\ Kingdom of Saudi Arabia \\ ${ }^{4}$ Radiotherapy and Nuclear Medicine Department, College of Medical Radiological Sciences, Sudan University \\ of Science and Technology, Khartoum, Sudan \\ Email: ${ }^{*}$ m.alhassen@sau.edu.sa
}

Received 16 November 2014; accepted 9 March 2015; published 11 March 2015

Copyright (C) 2015 by authors and Scientific Research Publishing Inc.

This work is licensed under the Creative Commons Attribution International License (CC BY).

http://creativecommons.org/licenses/by/4.0/

(c) (;) Open Access

\section{Abstract}

Multi-detector row computed tomography urography (MDCTU) becomes the imaging modality of choice for evaluation of the kidneys and urinary tract. The aim of this study was to discuss and illustrate the role of MDCTU, on a 32-row CT scanner in the evaluation a variety of entities that were frequently associated with microscopic hematuria in adults. This prospective cohort study was performed in the period of August 2013 to October 2014. Fifty positive participants to microscopic hematuria were examined at the radiology department of Alnilin Diagnostic Medical Center and Antalya Medical Center. Computed tomography urography (CTU) scanning was performed using two powerful performances, high speed multi-detector row on 32-row CT scanners (Siemens Healthcare Global, Somatom Emotion Duo Eco). Statistical analysis was done through the standard Statistical Package for the Social Sciences (SPSS Inc., Chicago, IL, USA) version 15 for windows. MDCTU established the correct cause of microscopic hematuria in $(44 ; 88 \%)$ of participants. In (6; $12 \%$ ) of participants, no cause of hematuria was identified based on the standard of references. The causes of hematuria in $(41 ; 82 \%)$ participants were diseases in the upper urinary tract, while urinary bladder neoplasms $(2 ; 4 \%)$ and diverticulum $(1 ; 2 \%)$ were the causes of hematuria $(3 ; 6 \%)$ in the lower urinary tract. Thirty two-row MDCTU scanner demonstrated satisfactory results in

\footnotetext{
${ }^{*}$ Corresponding author.
}

How to cite this paper: Mahmoud, M.A., Mahmoud, M.Z., Omer, M.A.A., Garalnabi, M.E.M., Abukonna, A. and Fagiri, M.A. (2015) Multi-Detector Row Computed Tomography Urography (MDCTU) in the Evaluation of Microscopic Hematuria in Adults. Open Journal of Radiology, 5, 20-27. http://dx.doi.org/10.4236/ojrad.2015.51004 
the investigation of microscopic hematuria, being able to demonstrate a wide spectrum of diseases affecting the urinary tract is the main advantage of the technique.

\title{
Keywords
}

\author{
Hematuria, Imaging, Three-Dimensional, Multi-Detector Computed Tomography, Urologic Diseases
}

\section{Introduction}

The prevalence of asymptomatic microscopic hematuria in adults ranges from 0.19 to 21 percent [1]. The range is wide because of differing definitions of clinically significant microscopic hematuria and the varying ages of the study populations. The incidence of neoplasm and moderately serious renal disease in these individuals is highly variable with age and sex but it is a major concern. Mohr et al. identified genitourinary neoplasms in (1\%) and moderately serious urological disease in another (18.2\%) of their patients with microscopic hematuria [2]. In a series of 200 patients, Carson et al. found neoplasms in 13\% and moderately serious renal disease in (35.5\%) [3]. In a select group of men 50 years or older who presented with asymptomatic micro hematuria, Messing et al. identified malignancies in (26\%) and significant urological disease in (53\%) [4].

Urine normally contains a few red blood cells, and microscopic hematuria generally is defined as one to ten red blood cells per high-power field of urine sediment [5]. The American Urological Association (AUA) defines clinically significant microscopic hematuria as three or more red blood cells per high power field on microscopic evaluation of urinary sediment from two of three properly collected urinalysis specimens [1] [6]. Each laboratory, however, establishes its own thresholds based on the method of detection used and in reference to healthy persons as controls. Microscopic hematuria, unlike gross hematuria, is often an incidental finding but may be associated with urologic malignancy in up to 10 percent of adults [7] [8]. Despite this risk, results of a recent study revealed that 39 to 90 percent of persons with microscopic hematuria on screening urinalysis received no follow-up testing [9]. Microscopic hematuria presents a challenging clinical scenario for family physicians. Obtaining a thorough history and physical examination and assessing each patient's risk factors for urothelial cancer can assist physicians in choosing how to proceed with radiographic evaluation of the upper urinary tract, urine cytology, or cystoscopy [9].

Many imaging modalities have been used in the evaluation of patients with hematuria. Historically, intravenous urography (IVU) has been the primary method of imaging in these patients [10] [11]. Currently, the examinations that are commonly used to evaluate patients with hematuria include IVU, ultrasonography (US), computed tomography (CT), magnetic resonance imaging (MRI), retrograde ureterography and pyelography, cystoscopy, and ureteroscopy [12].

Multi-detector row computed tomography urography (MDCTU) has become the imaging modality of choice for evaluation of the kidneys and urinary tract. There are numerous accepted indications for performing computed tomography urography (CTU). A very common role is in the work-up of microscopic or macroscopic hematuria. Causes of hematuria, which can be detected by CTU include, but are not limited to, urinary tract calculi (within the renal collecting systems, ureters, or bladder), benign and malignant renal masses (most common renal cell carcinomas), and urothelial tumors; most commonly transitional cell carcinomas (TCCs). CTU may also be used in the evaluation of the kidneys and upper urinary tracts for congenital anomalies, acquired or inflammatory benign conditions (such as renal papillary necrosis, renal tubular ectasia, and ureteritis cystica), and benign urinary tract masses (e.g., urothelial papillomas, inverted papillomas, and ureteral fibroepithelial polyps) [1] [5] [6] [13].

CTU can also be helpful in identifying the cause of an obstructed upper urinary tract, particularly in the determination of an intrinsic or extrinsic urinary tract etiology. Finally, post-surgical changes involving the urinary tract can be evaluated by CTU (e.g., follow-up evaluation of neobladders, ileal conduits, or reimplanted ureters) [1] [5] [6] [13].

In this article, authors apply the MDCTU technique, on a 32-row CT scanner in participants with hematuria to discuss and illustrate a variety of entities that are frequently associated with hematuria, including calculi, renal masses, papillary and caliceal abnormalities, renal pelvic and ureteral disease, bladder disease, and congenital anomalies. 


\section{Material and Methods}

\subsection{Selection and Description of Participants}

This prospective cohort study was performed in the period of August 2013 to October 2014. Positive participants to microscopic hematuria were examined at the radiology department of Alnilin Diagnostic Medical Center and Antalya Medical Center. Prior to participants examined, a formal approval was obtained from the Ethics and Scientific Committee of these medical centers and has therefore been performed in accordance with the ethical standards laid down in the 1964 Declaration of Helsinki and all subsequent revisions. After the nature of the procedure was fully explained, informed consents were obtained from participants and these radiology Departments.

The criteria for inclusion were three or more episodes of microscopic hematuria in urine per high-power field of urine sediment. Participants with a previously diagnosed cause of hematuria or dysmorphic red cells were excluded. A detailed history of stone disease, diabetes mellitus, sickle cell disease, hypertension, cardiovascular disease, stroke, nephrological diseases and/or bleeding tendencies due to hematological disorders or medications was made available by the referring physicians, as were laboratory data on urinalysis, cytology, urine culture, a hematological profile and sickle cell preparation.

Most patients had been examined by the urological surveillance protocol multiple times. In addition, reports or original images of intravenous urography (IVU) and computed tomography (CT) without and with intravenous contrast enhancement were made available.

\subsection{Scanning Parameters}

CTU scanning is performed extending from the top of the kidneys to the base of the bladder in an approximately 20 second breath-hold using powerful performance, high speed multi-detector row, on a 32-row CT scanner (Siemens Healthcare Global, Somatom Emotion Duo Eco).

Images were acquired with a $2.5 \mathrm{~mm}$ detector configuration and a non-overlapping slices-pitch of 1.5:1 (table speed $15 \mathrm{~mm} /$ rotation). For diagnostic evaluation, contiguous axial images are reconstructed with $5 \mathrm{~mm}$ slice thickness. When needed, $2.5 \mathrm{~mm}$ thin slices (slice profile $3.2 \mathrm{~mm}$ at full width at half maximum) with (50\%) overlap are obtained for reconstructing coronal and sagittal images of the ureters. Thinner slices are especially important in evaluation of renal vessels, and small and subtle renal abnormalities. The scan parameters for MDCTU on a 32-row CT scanner have been summarized in (Table 1).

\subsection{Multi-Detector Computed Tomography Urography (MDCTU) Imaging Protocol}

Protocol of study consisted of MDCTU on a 32-row CT scanner with certain scan sequences. A pre-enhancement CT was done from the upper kidney pole to $2 \mathrm{~cm}$ below the symphysis pubis using $5 \mathrm{~mm}$ collimation. The late arterial or early corticomedullary phase was recorded after injecting 100 to $150 \mathrm{ml}$ nonionic contrast me-

Table 1. Scanning parameters for the routine MDCTU protocol.

\begin{tabular}{|c|c|}
\hline \multicolumn{2}{|c|}{ Scanning parameters } \\
\hline Tube voltage (kVp) & 140 \\
\hline Tube current (mA) & $180-260$ \\
\hline Gantry rotation time & 0.8 second \\
\hline Beam pitch & $1.5: 1$ \\
\hline Detector configuration & $2.5 \mathrm{~mm}$ \\
\hline Table feed/rotation & $15 \mathrm{~mm} /$ rotation \\
\hline Slice thickness (routine study) & 5 mm (full width at half maximum) \\
\hline Slice thickness (for renal mass) & $2.5 \mathrm{~mm}$ (full width at half maximum) \\
\hline Reconstruction interval & $50 \%$ \\
\hline
\end{tabular}


dium, iothalimate meglumine or Ultravist Iopromide 300 (Schering, Berlin, Germany) at a rate of 3 to $5 \mathrm{ml}$ per second using a power injector with a 15 to 25 second delay or a Smart Prep Sequence (Siemens Healthcare Global, Somatom Emotion Duo Eco).

Collimation of $2 \mathrm{~mm}$ was used through the kidney with $3 \mathrm{~mm}$ collimation through the lower pelvis. Nephrographic phase in MDCTU was generated 90 to 160 seconds after contrast infusion with 3 to $5 \mathrm{~mm}$ collimation through the kidney and $5 \mathrm{~mm}$ collimation through the lower pelvis. An excretory phase sequence was recorded 4 to 8 minutes after contrast infusion from the upper kidney pole to $2 \mathrm{~cm}$ below the symphysis pubis with $5 \mathrm{~mm}$ collimation.

Patient in inspiration with an acquisition time of 18 to 24 seconds per scan or using a cluster technique of 5 contiguous images per 9 seconds of breath hold with an 8 second interposed pause. Table feed was 6 to $7.5 \mathrm{~mm}$ per second. In some instances with equivocal findings, reconstructions at $1.25 \mathrm{~mm}$ slice thickness were done. Digital images in 2 posterior oblique projections were generated after completing our standard sequences to provide additional information on the ureter. To facilitate three dimensional (3D) reformatting, orally administered contrast material was not used for this technique.

All images were interpreted at the standard soft tissue window setting. A complete sequence of images was also reviewed at standard bone window settings to identify coexistent bone pathology. Attenuation coefficient measurements were obtained using the maximum radius of radius of curvature (ROC) within the confines of the lesion. All interpretations were done by a senior genitourinary radiologist at each medical center. MDCTU on a 32-row CT scanner examination in progress was performed by the senior Radiodiagnostic Technologists in the radiology department of each medical center.

One concern about this comprehensive four sequence MDCTU technique is radiation dose to the patient. The four phases of the examination delivers an average median dose of approximately 5.54 RADS to the pelvis. This dose is significantly higher than the typical dose for IVU. To limit the dose, we decided not to cover the entire abdomen and pelvis on all phases.

\subsection{Statistics}

Data were initially summarized as mean \pm SD in a form of comparison tables and graphs. Statistical analysis was performed using the standard Statistical Package for the Social Sciences (SPSS Inc., Chicago, IL, USA) version 15 for windows.

\section{Results}

Study population comprised 50 positive participants to microscopic hematuria (40\% males and $60 \%$ females). Participants' ages ranged from 17 to 93 years; with a mean age of $(51.1 \pm 1.2)$ years (Table 2 and Figure 1$)$. Out of the examined participants, a total of 15 subjects were in the age group (50 - 60) years, representatives (30\%) of the population (Table 2).

The age group of (83 - 93) years was the smallest and represented only (4\%) of the population (Table 2 and Figure 1). The highest mean \pm SD of ages was (83 \pm 0.7$)$ years and found in the age group (83 - 93) years, while

Table 2. Distribution of participant's ages (years).

\begin{tabular}{cccc}
\hline Age ranges (years) & Frequency & Percentage (\%) & Mean \pm SD (years) \\
\hline $17-27$ & 4 & 8 & $18 \pm 0.8$ \\
$28-38$ & 7 & 14 & $30 \pm 0.9$ \\
$39-49$ & 9 & 18 & $41 \pm 1.5$ \\
$50-60$ & 15 & 30 & $51 \pm 1.9$ \\
$61-71$ & 9 & 18 & $62 \pm 1.5$ \\
$72-82$ & 4 & 8 & $73 \pm 0.8$ \\
$83-93$ & 2 & 4 & $83 \pm 0.7$ \\
Total & 50 & 100 & $51.1 \pm 1.2$ \\
\hline
\end{tabular}




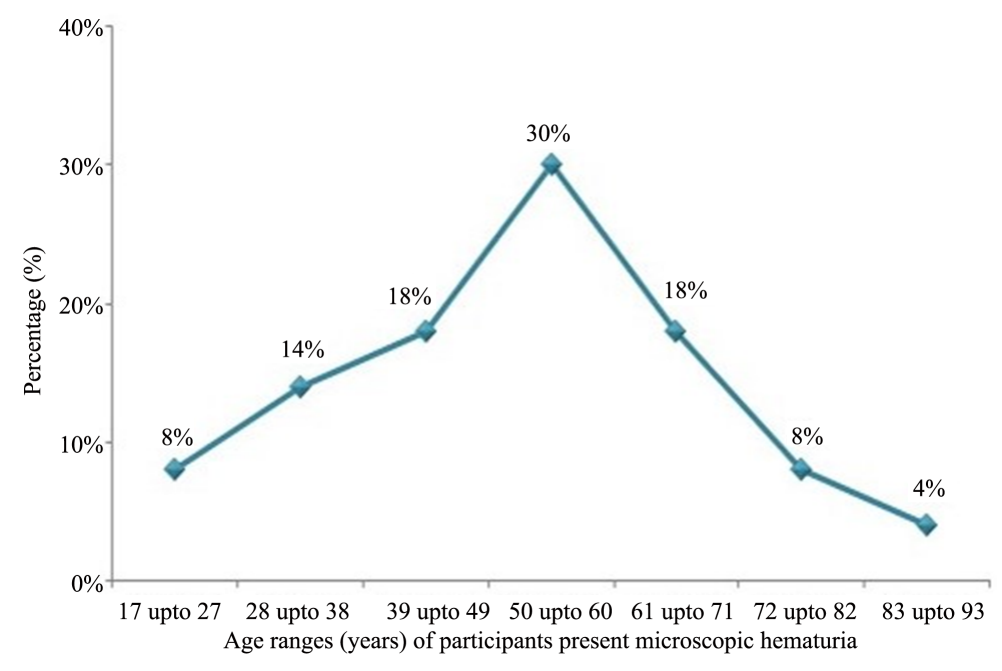

Figure 1. Microscopic hematuria percentage (\%) of incidence among different ages (years) of participants.

the lowest mean \pm SD of ages was $(18 \pm 0.8)$ years found in the age group (17 - 27) years (Table 2).

MDCTU on a 32-row CT scanner established the correct cause of microscopic hematuria in (44; 88\%) of participants. In $(6 ; 12 \%)$ of participants, no cause of hematuria was identified based on the standard of references (Table 3 and Figure 2).

The cause of hematuria in (41; 82\%) participants were diseases in the upper urinary tract (Table 3 and Figure 2) as inflammatory kidney lesions (2; 4\%); renal neoplasms (16; 32\%); calculous disease (12; 24\%); renal lesions with abnormal vascular patterns (6; 12\%); miscellaneous renal diseases $(4 ; 8 \%)$ and ureteral lesions (1; $2 \%)$. Urinary bladder neoplasms $(2 ; 4 \%)$ and diverticulum $(1 ; 2 \%)$ were the causes of hematuria $(3 ; 6 \%)$ in the lower urinary tract (Table 3 and Figure 2).

\section{Discussion}

Microscopic hematuria is a common urological problem with a wide range of causes, including infection, stone disease, tumors of the kidney and the urinary tract, drug toxicity and coagulopathy [14]. Traditional imaging evaluation of these patients included a cross-sectional study of the upper urinary tract (sonography, CT, or MRI) and IVU [10] [12] [15]. The results of our study demonstrated that a wide variety of causes for the hematuria could be successfully detected by MDCTU on a 32-row CT scanner.

The dilemma of how best to investigate patients with asymptomatic hematuria is reflected by the lack of conclusions on policy statements and recommendations for the evaluation of asymptomatic microhematuria in adults by the AUA best practice policy panel [16]. The frequency of the discovery of urological lesions during the follow-up of patients with, initially negative examinations supports the expanded use of imaging to augment the clinical investigation [2] [3]. Despite anecdotal reports lauding ultrasound and IVP for high accuracy in detecting upper tract lesions, recent investigations revealed grave shortcomings. Gray et al. found (100\%) sensitivity and (97.4\%) specificity for CT versus (60.5\%) sensitivity and (90.9\%) specificity for IVP for identifying urinary tract lesions [17]. Datta et al. reported a sensitivity of (63\%) for ultrasound for detecting bladder carcinoma with (99\%) specificity [18]. Frank et al. suggested that CT and CT urography may be the diagnostic modalities of choice for the evaluation of gross or microscopic hematuria [19]. Using a very thin collimation, the authors were able to depict the entire renal collecting system, the ureters and the urinary bladder in one acquisition, obtained in 7-12 seconds on the average, with a resolution that consider very close to that of IVU, although no direct comparison of these two studies was performed. Multiplanar reformations and 3D reconstructions provided images with excellent anatomic details, as well as IVU like images.

Although this study sample was small, MDCTU protocol successfully detected a total of (44; 88\%) conditions causing microscopic hematuria in 50 participants (Table 3 and Figure 2). The most common cause of hematuria in the study population was renal neoplasms, which was the cause of hematuria in (16; 32\%) of participants. The 


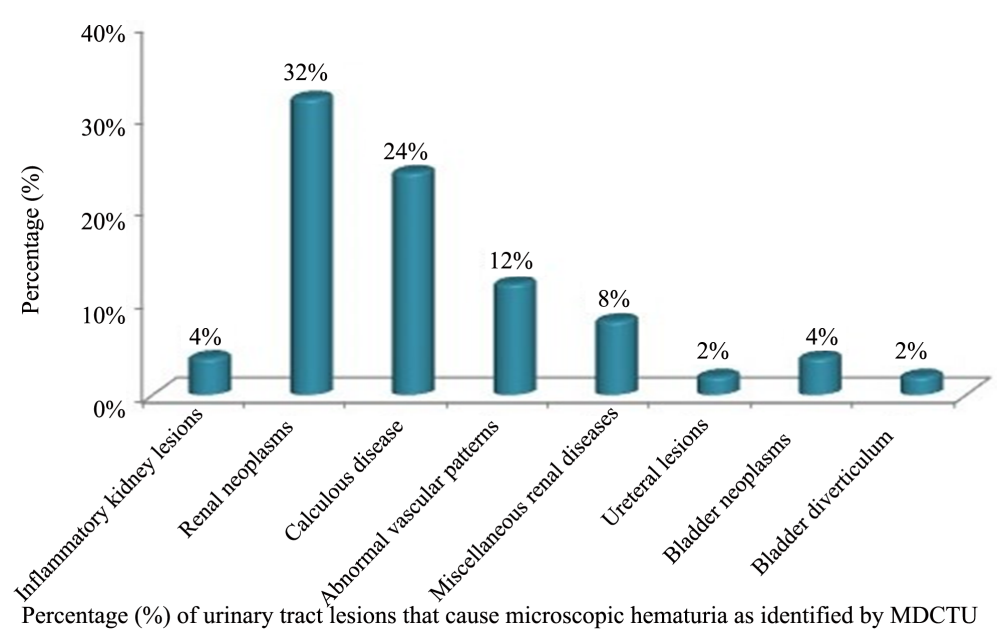

Figure 2. Percentage of urinary tract lesions cause microscopic hematuria and identified by MDCTU.

Table 3. Percentage of urinary tract lesions causing microscopic hematuria identified on MDCTU.

\begin{tabular}{|c|c|c|}
\hline \multicolumn{2}{|c|}{ Upper urinary tract } & \multirow{2}{*}{$\begin{array}{c}\text { Lower urinary tract } \\
\text { Urinary bladder }\end{array}$} \\
\hline Kidneys & Ureters & \\
\hline $\begin{array}{c}\text { Inflammatory kidney lesions (2; 4\%) } \\
\text { Pyonephrosis }(1 ; 2 \%) \\
\text { Inflammatory cyst }(1 ; 2 \%)\end{array}$ & \multirow{5}{*}{$\begin{array}{l}\text { Ureteral lesions }(1 ; 2 \%) \\
\text { Ureteritis cystica }(1 ; 2 \%)\end{array}$} & $\begin{array}{c}\text { Bladder neoplasms (2; 4\%) } \\
\text { Transitional cell carcinoma (1;2\%) } \\
\text { Lipoma (1;2\%) }\end{array}$ \\
\hline $\begin{array}{c}\text { Renal neoplasms (16; 32\%) } \\
\text { Renal cell carcinoma (6; 12\%) } \\
\text { Transitional cell carcinoma (4; 8\%) } \\
\text { Capsular sarcoma (3; 6\%) } \\
\text { Angiomyolipoma }(2 ; 4 \%) \\
\text { Oncocytoma }(1 ; 2 \%)\end{array}$ & & \\
\hline $\begin{array}{l}\text { Calculous disease }(12 ; 24 \%) \\
\text { Calculi }(10 ; 20 \%) \\
\text { Uric acid crystals in pyramids }(1 ; 2 \%) \\
\text { Nephrocalcinosis }(1 ; 2 \%)\end{array}$ & & $\begin{array}{c}\text { Bladder diverticulum (1; 2\%) } \\
\text { Sub-urethral diverticulum (1; 2\%) }\end{array}$ \\
\hline $\begin{array}{l}\text { Abnormal vascular patterns (6; } 12 \%) \\
\text { Infarcts (2; } 4 \%) \\
\text { Splenorenal shunts (cirrhosis) }(2 ; 4 \%) \\
\text { Anomalous left lumbar vein }(1 ; 2 \%) \\
\text { Retero-aortic left renal vein }(1 ; 2 \%)\end{array}$ & & \\
\hline $\begin{array}{l}\text { Miscellaneous renal diseases (4; 8\%) } \\
\text { Medullary sponge kidney (2; 4\%) } \\
\text { Renal atrophy (2; 4\%) }\end{array}$ & & \\
\hline
\end{tabular}

incidence of upper urinary tract pathology in the study population was high $(41 ; 82 \%)$, in compared to (3; 6\%) urinary bladder neoplasms (2; 4\%) and diverticulum (1;2\%)—were the causes of hematuria in the lower urinary tract. This result is surprising since tumors in these locations are uncommon. In a study of 1000 consecutive adult patients with asymptomatic hematuria in the absence of proteinuria [20], 73 patients were found to have transitional cell cancer as the cause of hematuria with 65 occurring in the bladder, five in the renal pelvis and three in the ureter. In a study of 1034 patients with asymptomatic microscopic hematuria [21], 14 urinary tract tumors were found with 13 arising in the bladder and one in the renal pelvis.

MDCTU has demonstrated satisfactory results in the detection of uroepithelial malignancies [6] [22]. Caoili et al. [5] detected 15 out of 16 foci of TCCs, including one lesion of $5 \mathrm{~mm}$ in maximal diameter. The same group of investigators [6] retrospectively reviewing 370 MDCTU examinations of patients suspected of urinary tract disease, identified 24 of 27 upper tract cancers, including five masses with a diameter equal or smaller than 5 $\mathrm{mm}$. In another series, Cowan et al. [23] performed MDCTU and retrograde pyelography in 106 high-risk pa- 
tients correctly identified all upper tract malignancies, with MDCTU proving more sensitive than retrograde pyelography (sensitivity: 98\% versus $79 \%$ ). In the same study only one bladder cancer was not detected. In another multi-institutional study [22] of 350 patients with hematuria four patients had bladder TCCs, one had an urachal adenocarcinoma and only one patient had TCC of the upper tract, all detected on MDCTU. The above groups of investigators used either a 4- or an 8-detector row CT scanner.

This study demonstrated that MDCTU on a 32-row CT scanner could detect upper and lower urinary tract malignancies, including lesions as renal cell carcinoma (6; 12\%), TCC (4; 8\%), capsular sarcoma (3; 6\%), angiomyolipoma (2; 4\%) and oncocytoma (1; 2\%) in the kidneys while pathologies as TCC (1; 2\%) and lipoma (1; $2 \%$ ) were detected in the urinary bladder, even though a larger number of participants are needed to support the above data. The satisfactory results of MDCTU on a 32-row CT scanner in the detection of the kidneys and urinary bladder neoplasms in this study, perhaps, would obviate the need of performing conventional cystoscopy in patients presenting with hematuria and positive results on MDCTU. Even though authors apply the MDCTU technique in patients with hematuria to discuss and illustrate a variety of entities that are frequently associated with hematuria, including calculi, renal masses, papillary and caliceal abnormalities, renal pelvic and ureteral disease, bladder disease, and congenital anomalies.

As limitation enrollment was dependent upon available CT time and therefore was not consecutive, this may have resulted in a selection bias. The fact that one radiologist in each of the two areas of study interpreted the CTU radiographs, considered as a limitation in study design. However, this was a necessary arrangement as it was our policy to interpret the CTU radiographs before the patient left the radiology department. In addition, the delay in performing CTU may have resulted in suboptimal opacification of the urinary tract. Issues of image resolution, radiation and cost relative to IVU and other imaging strategies will also need to be addressed. The goal would be to replace a series of radiological examinations with a single examination that could be obtained quickly and that would be highly accurate in detecting and excluding significant causes of painless haematuria.

\section{Conclusion}

In conclusion, contrast-enhanced MDCTU on a 32-row CT scanner performed with a combination of unenhanced, nephrographic phase, and excretory phase imaging can demonstrate a wide spectrum of disease in these participants with a single study. Unenhanced imaging provides optimal detection of calculi, a common cause of hematuria. In addition, the combination of unenhanced and nephrographic phase imaging provides an outstanding evaluation of renal masses. Findings at excretory phase imaging mimic IVU findings and allow excellent evaluation of the collecting systems and ureters. Bladder disease, a common cause of hematuria, is often well seen on unenhanced or excretory phase images, although cystoscopy may still be necessary. Although more experience and data are necessary, this protocol has the potential to provide accurate evaluation of patients with hematuria with a single comprehensive CT examination.

\section{Acknowledgements}

The authors would like to thank the staff of The Radiology Department of Alnilin Diagnostic Medical Center and Antalya Medical Center for their cooperation and support during data collection.

\section{References}

[1] McNicholas, M.M., Raptopoulos, V.D., Schwartz, R.K., Sheiman, R.G., Zormpala, A., et al. (1998) Excretory Phase CT Urography for Opacification of the Urinary Collecting System. American Journal of Roentgenology, 170, 12611267. http://dx.doi.org/10.2214/ajr.170.5.9574598

[2] Mohr, D.N., Offord, K.P., Owen, R.A. and Melton 3rd, L.J. (1986) Asymptomatic Microhematuria and Urologic Disease: A Population-Based Study. The Journal of the American Medical Association, 256, 224-229. http://dx.doi.org/10.1001/jama.256.2.224

[3] Carson, C.C., Segura, J.W. and Greene, L.F. (1979) Clinical Importance of Microhematuria. The Journal of the American Medical Association, 241, 149-150. http://dx.doi.org/10.1001/jama.241.2.149

[4] Messing, E.M., Young, T.B., Hunt, V.B., Emoto, S.E. and Wehbie, J.M. (1987) The Significance of Asymptomatic Microhematuria in Man 50 or More Years Old: Findings of a Home Screening Study Using Urinary Dipsticks. Journal of Urology, 137, 919-922.

[5] Caoili, E.M., Cohan, R.H., Korobkin, M., Platt, J.F., Francis, I.R., et al. (2002) Urinary Tract Abnormalities: Initial 
Experience with Multi-Detector Row CT Urography. Radiology, 222, 353-360. http://dx.doi.org/10.1148/radiol.2222010667

[6] Caoili, E.M., Cohan, R.H., Inampudi, P., Ellis, J.H., Shah, R.B., et al. (2005) MDCT Urography of Upper Tract Urothelial Neoplasms. American Journal of Roentgenology, 184, 1873-1881. http://dx.doi.org/10.2214/ajr.184.6.01841873

[7] Sultana, S.R., Goodman, C.M., Byrne, D.J. and Baxby, K. (1996) Microscopic Haematuria: Urological Investigation Using a Standard Protocol. British Journal of Urology, 78, 691-698.

http://dx.doi.org/10.1046/j.1464-410X.1996.01975.x

[8] Khadra, M.H., Pickard, R.S., Charlton, M., Powell, P.H. and Neal, D.E. (2000) A Prospective Analysis of 1930 Patients with Hematuria to Evaluate Current Diagnostic Practice. Journal of Urology, 163, 524-527. http://dx.doi.org/10.1016/S0022-5347(05)67916-5

[9] Sutton, J.M. (1990) Evaluation of Hematuria in Adults. The Journal of the American Medical Association, 263, 24752480. http://dx.doi.org/10.1001/jama.263.18.2475

[10] Amis, E.S. (1999) Epitaph for the Urogram. Radiology, 213, 639-640. http://dx.doi.org/10.1148/radiology.213.3.r99dc47639

[11] McNicholas, M.M., Raptopoulos, V.D., Schwartz, R.K., Sheiman, R.G., Zormpala, A., et al. (1998) Excretory Phase CT Urography for Opacification of the Urinary Collecting System. American Journal of Roentgenology, 170, 12611267. http://dx.doi.org/10.2214/ajr.170.5.9574598

[12] Grossfeld, G.D., Litwin, M.S., Wolf Jr., J.S., Hricak, H., Shuler, C.L., et al. (2001) Evaluation of Asymptomatic Microscopic Hematuria in Adults: The American Urological Association Best Practice Policy—Part II: Patient Evaluation, Cytology, Voided Markers, Imaging, Cystoscopy, Nephrology Evaluation, and Follow-Up. Urology, 57, 604-610. http://dx.doi.org/10.1016/S0090-4295(01)00920-7

[13] Chow, L.C. and Sommer, F.G. (2001) Multidetector CT Urography with Abdominal Compression and Three-Dimensional Reconstruction. American Journal of Roentgenology, 177, 849-855. http://dx.doi.org/10.2214/ajr.177.4.1770849

[14] Grossfeld, G.D., Litwin, M.S., Wolf, J.S., Hricak, H., Shuler, C.L. and Carroll, P.R. (2001) Evaluation of Asymptomatic Microscopic Hematuria in Adults: The American Urological Association Best Practice Policy—Part I: Definition, Detection, Prevalence, and Etiology. Urology, 57, 599-603. http://dx.doi.org/10.1016/S0090-4295(01)00919-0

[15] Webb, J.A. (1997) Imaging in Haematuria. Clinical Radiology, 52, 167-171. http://dx.doi.org/10.1016/S0009-9260(97)80269-3

[16] Grossfeld, G.D., Wolf Jr., J.S., Litwan, M.S., Hricak, H., Shuler, C.L., et al. (2001) Asymptomatic Microscopic Hematuria in Adults: Summary of the AUA Best Practice Policy Recommendations. American Family Physician, 63, 1145-1154.

[17] Gray, C.L., Ward, J.F., Sears, S.T., Puckett, M.F., Kane, C.J. and Amling, C.L. (2002) Prospective Comparison of Computerized Tomography and Excretory Urography in the Initial Evaluation of Asymptomatic Microhematuia. Journal of Urology, 168, 2457-2460. http://dx.doi.org/10.1016/S0022-5347(05)64167-5

[18] Datta, S.N., Allen, G.M., Evans, R., Vaughton, K.C. and Lucas, M.G. (2002) Urinary Tract Ultrasonography in the Evaluation of Haematuria-A Report of over 1000 Cases. Annals of the Royal College of Surgeons of England, 84, 203-205.

[19] Dechet, C.B., Zincke, H., Sebo, T.J., King, B.F., LeRoy, A.J., et al. (2003) Prospective Analysis of Computerized Tomography and Needle Biopsy with Permanent Sectioning to Determine the Nature of Solid Renal Masses in Adults. Journal of Urology, 169, 71-74.

[20] Mariani, A.J., Mariani, M.C., Macchioni, C., Stams, U.K., Hariharan, A., et al. (1989) The Significance of Adult Hematuria: 1000 Hematuria Evaluations Including a Risk-Benefit and Cost-Effectiveness Analysis. Journal of Urology, 141, 350-355.

[21] Murakami, S., Igarashi, T., Hara, S. and Shimazaki, J. (1990) Strategies for Asymptomatic Microscopic Hematuria: A Prospective Study of 1034 Patients. Journal of Urology, 144, 99-101.

[22] Lang, E.K., Macchia, R.J., Thomas, R., Ruiz-Deya, G., Watson, R.A., et al. (2002) Computerized Tomography Tailored for the Assessment of Microscopic Hematuria. Journal of Urology, 167, 547-554. http://dx.doi.org/10.1016/S0022-5347(01)69083-9

[23] Cowan, N.C., Turney, B.W., Taylor, N.J., McCarthy, C.L. and Crew, J.P. (2007) Multidetector CT Urography for Diagnosing Upper Urinary Tract Urothelial Tumour. BJU International, 99, 1363-1370. http://dx.doi.org/10.1111/j.1464-410X.2007.06766.x 